Werner Lambersy est né le 16 novembre 1941 à Anvers. Un père engagé dans la Waffen SS en 1942. Une mère de tradition juive et franc-maçonne qui s'éloignera de son époux et s'installera à Bruxelles en 1944 avec son jeune fils et sa mère. Le français devient la langue de la famille. Études au Collège Saint-Michel à Bruxelles. Divers métiers. Une vie professionnelle de 1960 à 2002. Deux mariages. Une intense production littéraire, théâtrale et poétique, des essais, des livres d'artistes. Depuis 1982, le poète vit à Paris. Il a été attaché au centre Wallonie-Bruxelles pour la promotion des Lettres belges pendant une vingtaine d'années. Il a voyagé sur quatre continents et rencontré de belles amitiés.

\title{
Choix de poèmes
}

La neige exigeait la rigueur

Les formes

Nécessaires et belles

Étaient simples

L'accord régnait

Entre la ligne et l'angle

Entre montagnes et vide dans

L'azur

Ici le repas

Qu'allait servir le dieu nu

Épouserait la perfection

Comme lumière et ombre

Se prolongent.

(l'Arche) 
La mort ni le poème

$\mathrm{Ne}$ sont le silence

Mais sans silence

Ils ne sont rien

La mort

C'est apprendre ce

Qu'un silence peut

Dire

Le poème

C'est dire et redire

Cet apprentissage

Quand le silence

Se tait

C'est que la parole

Est prête

Quand la parole est un silence

c'est qu'un poème

va parler (Athée provisoire)

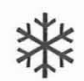


C'est à pied

Que l'on va vers ce temps

Non compté

Par des chemins de terre

Qu'une farine d'astres

Rend doux

Vers des idoles simples

Choses

De rencontre

Et sans pouvoirs attendus

Sinon ce bruit silencieux

Dont la matière du poème Est faite.

(Komboloi)

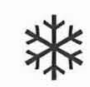

Au temps

Où le temps n'était pas

Où s'aimer était aimer

Le tout

Lorsque rien ne tremblait

Pour l'autre

Un bol

Aurait servi dit-on

Pour écoper du néant

La part où épaissir

Le vide.

(Un bol comme image du monde) 


\section{*}

Architectes et maçons

Montèrent des murs

Depuis le trou des ténèbres

On n'aurait pas pu

Glisser une feuille

Entre les blocs

Les soleils dansèrent

Sur les marches du seuil

Et les étoiles

Finirent les fenêtres

Couvreurs et charpentiers

Des crépuscules

Achevèrent le travail

Tous se dirent

Que d'être vide ainsi

Rendait le temple plus beau

Aussi s'en allèrent-ils

Sans rien dire du poème.

(L'horloge de Linné) 